\title{
RAÇÕES ÚMIDAS E ÁGUA DE CONSUMO E RACÃO COM EDULCORANTE PARA LEITÕES DESMAMADOS AOS 21 DIAS E EFEITOS SOBRE O DESEMPENHO ATÉ OS 90 KG DE PESO VIVO
}

\author{
WET FEEDING AND WATER AND RATIONS WITH SWEETENER FOR \\ PIGLETS WEANED AT 21 DAYS AND ITS EFFECTS ON \\ PERFORMANCE AT 90 KG LIVE WEIGHT
}

\author{
Caio Abércio da Silva ${ }^{1}$ Rodolfo Nascimento Kronka ${ }^{2}$ Maria Cristina Thomaz ${ }^{2}$ \\ Sérgio Nascimento Kronka ${ }^{2}$ Wilson Castillo Soto $^{3}$ Luís Euquério de Carvalho
}

RESUMO

\begin{abstract}
Um experimento foi realizado visando avaliar o fornecimento de rações úmidas e de água de consumo e rações com edulcorante para leitões desmamados e seus efeitos sobre o desempenho até o $90 \mathrm{~kg}$ de peso vivo. Foram utilizados 32 leitões Large White x Landrace, desmamados aos 21 dias, submetidos, durante a fase inicial I (21 a 42 dias de idade), a 8 tratamentos correspondentes à combinação dos fatores: forma de apresentação da ração (seca e úmida), tipo de ração (sem e com edulcorante) e água de consumo (sem e comedulcorante). Foram avaliados a ocorrência de diarréia até o $10^{\circ}$ dia pós-desmame, $o$ ganho diário de peso $(G D P)$, o consumo diário de ração $(C D R) e$ a conversão alimentar $(C A)$ até os $90 \mathrm{~kg}$ de peso vivo. $O$ consumo diário de água (CDA) foi avaliado na fase inicial I. O delineamento foi em blocos ao acaso, com arranjo fatorial 23, com quatro repetições, sendo as médias comparadas pelo teste de Tukey e a incidência de diarréia pelo teste de qui-quadrado. Foram observadas diferenças $(P<0,05)$, na fase inicial I, para o CDA para os grupos tratados com ração seca e para o CDR para os animais que receberam água com edulcorante. A ocorrência de diarréia foi maior $(P<0,05)$ para os animais tratados com ração seca. $O$ desempenho até os $90 \mathrm{~kg}$ de peso vivo foi semelhante entre os fatores $(P>0,05)$. $O$ experimento demonstrou que os tratamentos dirigidos na fase pós-desmame são insuficientes para melhorar os resultados até os $90 \mathrm{~kg}$ de peso vivo.
\end{abstract}

Palavras-chave: suínos, rações úmidas, água, edulcorante, diarréia.

\section{SUMMARY}

An experiment was conducted to evaluate the wet feeding and water and rations with sweetener for piglets weaned and its effects on performance at $50 \mathrm{~kg}$ live weight. Thirty two Large white $x$ Landrace, castrated male piglets weaned at 21 days and allocated during the initital phase 1 (21 to 42 days of age) were used in 8 treatments that were combinations with different types of diet (dry and wet), sweetener in the diet (with and without) and two types of drinking water (with and without sweetener). Diarrhea incidence at 10 days after weaning, daily weight gain, daily ration intake and feed convertion up to $90 \mathrm{~kg}$ were evaluated. Daily water intake was evaluated during the initial phase I. A randomized block design to study the factorial $2^{3}$ arrangement was used, with four replications. Means were compared by the Tukey test and diarrhea incidence by the chisquare test. The results showed significant differences $(P<0.05)$ in daily water intake for dry diet and daily ration intake for water with sweetener. Diarrhea incidence was significantly greater $(P<0.05)$ for dry diet than others treatments. The performance was similar $(P>0.05)$ between factors up to $90 \mathrm{~kg}$ live weight. The experiment indicated that the treatments applied to weaned piglets were insufficient to improve the performance at $90 \mathrm{~kg}$ live weight.

Key words: swine, wet feeding, water, sweetener, diarrhea.

\section{INTRODUÇÃO}

Um grande número de trabalhos tem orientado o estímulo do consumo de ração pós-

\footnotetext{
${ }^{1}$ Médico Veterinário, Doutor, Universidade Estadual de Londrina, Departamento de Zootecnia, 86051-970, Londrina, PR. Email: casilva@npd.uel.br. Autor para correspondência.

${ }^{2}$ Engenheiros Agrônomos, Doutores, Universidade Estadual Paulista (UNESP), Faculdade de Ciências Agrárias e Veterinárias (FCAV) Campus de Jaboticabal.

${ }^{3}$ Alunos de Pós-graduação em Zootecnia da UNESP, FCAV, Campus de Jaboticabal.
} 
desmame. Os efeitos no período conduzem a uma maior produção enzimática e melhora a digestão, promovendo maior consumo de ração com conseqüente aumento no ganho de peso (MAKKING et al., 1994). Segundo ARMSTRONG \& CLAWSON (1980), o baixo desempenho no pósdesmame não deve ser atribuído à ineficiente conversão alimentar e sim ao baixo consumo, o que deve gerar preocupação com o mesmo.

Através da verificação de diferentes fatores que afetam a ingestão de ração dos leitões recém-desmamados, grande atenção tem sido dirigida aos efeitos da água sobre o aumento de consumo, seja pela sua inclusão nas rações (HEIMIG, 1996, FREITAS et al., 1997), seja induzindo o seu consumo nos bebedouros através do uso de edulcorantes (STOCKILL, 1990, MAENZ et al., 1993). STOCKILL (1990) observou que a adição de edulcorante na água proporcionou um aumento de duas a três vezes no consumo nos três primeiros dias após o desmame, havendo, conseqüentemente, aumento no consumo de ração e melhora no desempenho dos leitões na fase, ocasionando um maior desenvolvimento até a fase de crescimento. Há tempo, pesquisadores têm avaliado também os sistemas de alimentação com elevada participação de água para leitões desmamados precocemente. Essas alternativas alimentares ganharam muitos adeptos, tendo em vista a aparente receptividade fisiológica dos leitões para rações com alto teor de umidade (HEIMIG, 1996).

Trabalhos indicaram um maior consumo de rações líquidas em relação às secas (HEIMIG, 1996). Freqüentemente, os valores de consumo são $35 \%$ maiores durante os primeiros 7 dias depois do desmame, e para um período de 28 dias depois do desmame com 4 semanas, a melhora no consumo tem sido de 9,5 a 11,0\% (ALIMENTO..., 1994).

Apoiados nos conceitos anátomofisiológicos e visando estimular o consumo de alimento, os efeitos positivos e as ações dos flavorizantes na nutrição dos leitões foram estudados por CUNHA (1977) e WHITTEMORE (1993) que provaram sua eficiência em promover o consumo, o desenvolvimento precoce do sistema digestivo e, consequientemente, o desempenho. Nesse sentido, este trabalho visa fornecer informações sobre os resultados da indução do consumo hídrico e de ração pelo uso de rações úmidas e de edulcorantes na água e na ração sobre o desempenho de leitões desmamados aos 21dias de idade e os efeitos residuais desses tratamentos sobre a performance nas fases de crescimento e terminação.

\section{MATERIAL E MÉTODOS}

A unidade física constituiu-se de um galpão de alvenaria com parede lateral de $1,00 \mathrm{~m}$ de altura, com 32 baias individuais de $2,55 \mathrm{~m}^{2}(1,50 \mathrm{x}$ $1,70 \mathrm{~m})$, separados por divisórias de ferro. Foram utilizados bebedouros tipo taça (modelo SUIN SN300 - Industrial Agrícola Suin Ldta.), regulados para uma vazão de $600 \mathrm{~m} \ell /$ minuto, acoplados a um reservatório plástico individual com capacidade para 10 litros destinados à medição do consumo de água para cada animal.

Foram utilizados 32 leitões cruzados Large White $x$ Landrace, machos castrados, desmamados aos 21 dias de idade, com peso médio de $6,7 \mathrm{~kg}$. O experimento foi iniciado por ocasião da desmama. As seguintes fases foram consideradas na seqüência do experimento: fase inicial I (21 a 42 dias), inicial II (43 a 56 dias), inicial III (57 a 70 dias), crescimento (71 dias até $50 \mathrm{~kg}$ de peso vivo) e terminação (50kg até $90 \mathrm{~kg}$ de peso vivo).

O fornecimento de água e de ração ao longo de todo o experimento, para todos os tratamentos, foi ad libitum. Para os tratamentos onde as rações foram oferecidas sob apresentação úmida (água + ração), procedeu-se a adição de água no momento do fornecimento da ração aos animais.

Os tratos alimentares foram realizados às $7: 30,11: 30,14: 30$ e 18:00 horas. As rações utilizadas nos experimentos foram formuladas visando atender ao mínimo as exigências estabelecidas pelo NRC (1988) para as fases compreendidas entre 5 e $90 \mathrm{~kg}$ de peso vivo. As fórmulas e os níveis calculados das rações utilizadas nas fases inicial I, II e III, crescimento e terminação estão apresentadas na tabela 1 .

Os tratamentos correspondentes às rações com inclusão de água obedeceram à relação de mistura de 2 partes de ração para 1 parte de água (v/v). A densidade da ração foi determinada previamente para conhecimento de seu volume para ajuste da mistura com a água. Para os tratamentos cujas rações foram confeccionadas com o edulcorante, foi utilizada a sacarina sódica (SUCRAM 200 - Degussa - Divisão Química), na dose de $200 \mathrm{~g}$ por tonelada de ração, e nos tratamentos em que a água de consumo foi oferecida com edulcorante, utilizou-se o mesmo produto na dose de $200 \mathrm{~g}$ por 1000 litros de água.

Os tratamentos experimentais foram conduzidos durante as 3 primeiras semanas do experimento (fase inicial I), correspondendo a: T1 Ração seca sem edulcorante e água de bebida sem edulcorante; T2 - Ração seca sem edulcorante e água de bebida com edulcorante; T3 - Ração seca com edulcorante e água de bebida sem edulcorante; T4 Ração seca com edulcorante e água de bebida com 
Tabela 1 - Composição das rações experimentais (\%).

\begin{tabular}{|c|c|c|c|c|c|}
\hline Ingrediente (\%) & Inicial I & Inicial II & Inicial III & Crescimento & Terminação \\
\hline Milho comum & 52,679 & 56,390 & 60,182 & 74,966 & 78,145 \\
\hline Farelo de soja & 20,685 & 24,035 & 22,800 & 20,746 & 18,180 \\
\hline Levedura seca & 5,000 & 3,000 & 3,000 & --- & -- \\
\hline Soro de leite & 5,000 & 5,000 & 5,000 & --- & --- \\
\hline Leite em pó & 10,000 & 4,000 & 2,000 & --- & -- \\
\hline Açúcar & -- & 2,000 & 2,000 & -- & -- \\
\hline Óleo de soja & 1,870 & 1,594 & 1,400 & 1,152 & 0,846 \\
\hline Fosfato bicálcico & 2,250 & 1,846 & 1,650 & 1,370 & 1,431 \\
\hline Calcário & 0,500 & 0,417 & 0,344 & 0,897 & 0,686 \\
\hline Sal comum & 0,250 & 0,250 & 0,250 & 0,300 & 0,300 \\
\hline Premix mineral $^{1}$ & 0,240 & 0,240 & 0,240 & 0,200 & 0,200 \\
\hline $\begin{array}{l}\text { Premix } \\
\text { vitamínico }\end{array}$ & $0,350^{2}$ & $0,300^{2}$ & $0,300^{2}$ & $0,200^{3}$ & $0,150^{4}$ \\
\hline Lisina & 0,479 & 0,341 & 0,250 & 0,169 & 0,062 \\
\hline Metionina & 0,207 & 0,087 & 0,084 & -- & -- \\
\hline Óxido de zinco & 0,180 & 0,200 & 0,200 & --- & --- \\
\hline Aditivo 5 & 0,300 & 0,300 & 0,300 & -- & --- \\
\hline \multicolumn{6}{|c|}{ Composição nutricional $^{6}$} \\
\hline $\mathrm{EM}(\mathrm{kca} \ell / \mathrm{kg})$ & 3.250 & 3.250 & 3.250 & 3.260 & 3.260 \\
\hline Proteína (\%) & 20,00 & 19,00 & 18,00 & 16,00 & 15,00 \\
\hline Cálcio $(\%)$ & 1,00 & 0,80 & 0,70 & 0,75 & 0,70 \\
\hline Fósforo (\%) & 0,80 & 0,70 & 0,65 & 0,57 & 0,52 \\
\hline Lisina (\%) & 1,50 & 1,30 & 1,15 & 0,90 & 0,75 \\
\hline
\end{tabular}

${ }^{1}$ Premix mineral por kg de produto: Fe, 40g; Cu, 35g; Mg, 20g; Zn, 40g; Co, 360mg; I, 840mg; Se, 120mg.

${ }^{2}$ Premix vitamínico por kg de produto: vit.A, 4.000.000 UI; vit.D3 1.000.000 UI;vit.E, 5.000mg;vit.K3, 3.500mg; vit.B2, 3,8mg; vit.B12, 9mcg; ácido pantotênico, 4mg; niacina, 14 g; biotina, 0,04mg; colina, $100 \mathrm{mg}$; antioxidante, $60 \mathrm{~g}$.

${ }^{3}$ Premix vitamínico por kg de produto: vit.A, $1.500 .000 \mathrm{UI}$; vit.D3 3.500.000 UI; vit.E, $4.000 \mathrm{mg}$; vit.K3, 1.250mg; vit.B2, 200mcg; vit.B12, $7 \mathrm{mcg}$; ácido pantotênico, $3 \mathrm{mg}$; niacina, 0,02mg; biotina, $0,02 \mathrm{mg}$; colina, $25 \mathrm{mg}$; antioxidante, $60 \mathrm{~g}$.

${ }^{4}$ Premix vitamínico por kg de produto: vit.A, 1.200.000 UI; vit.D3 280.000 UI; vit.E, $4.000 \mathrm{mg}$; vit.K3, $1.000 \mathrm{mg}$; vit.B2, $2.000 \mathrm{mcg}$; vit.B12, $7 \mathrm{mcg}$; ácido pantotênico, $3 \mathrm{mg}$; niacina, $10 \mathrm{mg}$; biotina, $100 \mathrm{mcg}$; colina, $25 \mathrm{mg}$; antioxidante, $60 \mathrm{~g}$.

${ }^{5}$ Aditivo por kg de produto: vit. A, $220.000 \mathrm{UI}$; vit. D3, $40.000 \mathrm{UI}$; vit. K3, 800mg; vit. B2, 250mg; vit.B12, 120mcg; ácido pantotênico, $850 \mathrm{mg}$; niacina, $1.600 \mathrm{mg}$, biotina, $7,350 \mathrm{mcg}$; tiamina, 5mg; vit. B6, 50mg; colina, $5.000 \mathrm{mg}$; lisina, $200 \mathrm{mg}$; metionina, $3.000 \mathrm{mg}$; clorotetraciclina, $20.000 \mathrm{mg}$; sulfametazina, $20.000 \mathrm{mg}$; penicilina, $10.000 \mathrm{mg}$; antioxidante, $2.000 \mathrm{mg}$.

${ }^{6}$ Valores calculados segundo EMBRAPA (1991).

edulcorante; T5 - Ração úmida sem edulcorante e água de bebida sem edulcorante; T6 - Ração úmida sem edulcorante e água de bebida com edulcorante; T7 - Ração úmida com edulcorante e água de bebida sem edulcorante; T8 - Ração úmida com edulcorante e água de bebida com edulcorante.

Nas fases subseqüentes, até os $90 \mathrm{~kg}$ de peso vivo, todos os animais foram mantidos nos grupos para a avaliação do efeito residual dos tratamentos adotados na fase inicial I. Todos os animais receberam ração com apresentação seca farelada específicas para cada fase. A água de consumo para todos os animais foi isenta de edulcorante a partir dos 42 dias de idade.

Foram avaliados o ganho diário de peso (GDP) de cada animal para cada fase, o consumo diário de ração (CDR) e de água $(C D A)$ e a conversão alimentar (CA). Foram também computados o número de dias necessários para cada animal atingir $50 \mathrm{~kg}$ de peso vivo (início da fase de terminação) e o número de dias para atingir o peso de abate (90kg de peso vivo).

Quanto à incidência de diarréia, durante os 10 primeiros dias da fase inicial I, os leitões foram examinados clinicamente duas vezes, uma vez pela manhã (9:00 horas) e à tarde (18:00 horas), e as fezes foram classificadas em normais (leitão sem diarréia), como pastosas (leitão sem diarréia) e como líquidas (leitão com diarréia), conforme metodologia descrita por MORES et al. (1990) e SONCINI \& MADUREIRA (1998).

O delineamento experimental foi em blocos casualizados com um arranjo fatorial 2 X 2 X 2 (sendo 2 tipos de ração, 2 tipos de ração e 2 tipos de água) com 4 repetições. As médias dos tratamentos foram comparadas pelo teste de Tukey. Para a incidência de diarréia, os dados foram comparados pelo teste do qui-quadrado.

\section{RESULTADOS E DISCUSSÃO}

As médias do GPD, CDR, CA e CDA na fase inicial I estão apresentados na tabela 2. Os resultados demonstrados na tabela 2 indicam diferença $(\mathrm{P}<0,05)$ na variável CDR para o fator água, sendo observado maior consumo de ração para os animais que receberam água com edulcorante. Esse maior consumo de ração explica, conseqüentemente, o superior GPD para o fator água com edulcorante, embora esta diferença não tenha sido significativa. Não houve, contudo, interação entre os fatores para a variável CDR.

Para a CA e para o GPD não foram observadas diferenças $(\mathrm{P}>0,05)$ dentro de cada fator, o mesmo ocorrendo com a interação entre eles (Tabela 2). Para o fator ração (com e sem edulcorante) não foi observada diferença entre os grupos para todos os parâmetros avaliados, não obstante ocorreram tendências de vantagens para as rações com edulcorante, sugerindo sua eficiência para promover o consumo (CUNHA, 1977, WHITTEMORE, 1993).

Possivelmente, a ausência de diferença $(\mathrm{P}>0,05)$ para este fator esteja relacionado com o fato de que as rações na fase inicial I apresentaram elevados níveis de produtos lácteos (soro de leite e 
Tabela 2 - Efeitos dos tratamentos sobre o ganho de peso diário (GPD), consumo diário de ração (CDR), conversão alimentar (CA) e consumo diário de água (CDA) na fase inicial I.

\begin{tabular}{lcccc}
\hline Fatores & GPD $(\mathrm{g})$ & CDR $(\mathrm{g})$ & $\mathrm{CA}$ & $\mathrm{CDA}(\mathrm{m} \ell)$ \\
\hline Ração seca & $347^{\mathrm{a}}$ & $520^{\mathrm{a}}$ & $1,543^{\mathrm{a}}$ & $1.075^{\mathrm{a}}$ \\
Ração úmida & $344^{\mathrm{a}}$ & $521^{\mathrm{a}}$ & $1,602^{\mathrm{a}}$ & $914^{\mathrm{b}}$ \\
Ração sem edulcorante & $332^{\mathrm{a}}$ & $507^{\mathrm{a}}$ & $1,575^{\mathrm{a}}$ & $984^{\mathrm{a}}$ \\
Ração com edulcorante & $359^{\mathrm{a}}$ & $533^{\mathrm{a}}$ & $1,570^{\mathrm{a}}$ & $1.005^{\mathrm{a}}$ \\
Água sem edulcorante & $319^{\mathrm{a}}$ & $485^{\mathrm{b}}$ & $1,578^{\mathrm{a}}$ & $962^{\mathrm{a}}$ \\
Água com edulcorante & $372^{\mathrm{a}}$ & $555^{\mathrm{a}}$ & $1,567^{\mathrm{a}}$ & $1.028^{\mathrm{a}}$ \\
\hline
\end{tabular}

Em cada coluna, para cada fator, médias seguidas de letras distintas diferem entre si $(\mathrm{P}<0,05)$ pelo teste de Tukey.

Tabela 3 - Efeitos dos tratamentos sobre o ganho de peso diário (GPD), consumo diário de ração (CDR), conversão alimentar (CA) e consumo diário de água (CDA) nas fases inicial II e III, crescimento, terminação e período total.

\begin{tabular}{|c|c|c|c|}
\hline Fatores & GPD $(g)$ & $\mathrm{CDR}(\mathrm{g})$ & $\mathrm{CA}$ \\
\hline & \multicolumn{3}{|c|}{ Fase inicial II } \\
\hline Ração seca & $706^{\mathrm{a}}$ & $1.288^{\mathrm{a}}$ & $1,818^{\mathrm{a}}$ \\
\hline Ração úmida & $649^{a}$ & $1.228^{\mathrm{a}}$ & $1,907^{\mathrm{a}}$ \\
\hline Ração sem edulcorante & $693^{\mathrm{a}}$ & $1.258^{\mathrm{a}}$ & $1,824^{\mathrm{a}}$ \\
\hline Ração com edulcorante & $662^{a}$ & $1.258^{\mathrm{a}}$ & $1,901^{\mathrm{a}}$ \\
\hline Água sem edulcorante & $658^{a}$ & $1.214^{\mathrm{a}}$ & $1,844^{\mathrm{a}}$ \\
\hline \multirow[t]{2}{*}{ Água com edulcorante } & $697^{\mathrm{a}}$ & $1.302^{\mathrm{a}}$ & $1,878^{\mathrm{a}}$ \\
\hline & \multicolumn{3}{|c|}{ Fase inicial III } \\
\hline Ração seca & $795^{\mathrm{a}}$ & $1.648^{\mathrm{a}}$ & $2,191^{\mathrm{a}}$ \\
\hline Ração úmida & $798^{a}$ & $1.628^{\mathrm{a}}$ & $2,070^{\mathrm{a}}$ \\
\hline Ração sem edulcorante & $816^{\mathrm{a}}$ & $1.636^{\mathrm{a}}$ & $2,115^{\mathrm{a}}$ \\
\hline Ração com edulcorante & $777^{\mathrm{a}}$ & $1.640^{\mathrm{a}}$ & $2,147^{\mathrm{a}}$ \\
\hline Água sem edulcorante & $777^{\mathrm{a}}$ & $1.635^{\mathrm{a}}$ & $2,219^{\mathrm{a}}$ \\
\hline \multirow[t]{2}{*}{ Água com edulcorante } & $816^{\mathrm{a}}$ & $1.641^{\mathrm{a}}$ & $2,042^{\mathrm{a}}$ \\
\hline & \multicolumn{3}{|c|}{ Fase de crescimento } \\
\hline Ração seca & $850^{\mathrm{a}}$ & $2.564^{\mathrm{a}}$ & $3,024^{\mathrm{a}}$ \\
\hline Ração úmida & $794^{\mathrm{a}}$ & $2.464^{\mathrm{a}}$ & $3,134^{\mathrm{a}}$ \\
\hline Ração sem edulcorante & $822^{\mathrm{a}}$ & $2.467^{\mathrm{a}}$ & $3,022^{\mathrm{a}}$ \\
\hline Ração com edulcorante & $822^{a}$ & $2.561^{\mathrm{a}}$ & $3,136^{\mathrm{a}}$ \\
\hline Água sem edulcorante & $816^{\mathrm{a}}$ & $2.547^{\mathrm{a}}$ & $3,147^{\mathrm{a}}$ \\
\hline \multirow[t]{2}{*}{ Água com edulcorante } & $827^{\mathrm{a}}$ & $2.481^{\mathrm{a}}$ & $3,011^{\mathrm{a}}$ \\
\hline & \multicolumn{3}{|c|}{ Fase de terminação } \\
\hline Ração seca & $915^{\mathrm{a}}$ & $2.891^{\mathrm{a}}$ & $3,177^{\mathrm{a}}$ \\
\hline Ração úmida & $864^{\mathrm{a}}$ & $2.716^{\mathrm{a}}$ & $3,176^{\mathrm{a}}$ \\
\hline Ração sem edulcorante & $930^{\mathrm{a}}$ & $2.833^{\mathrm{a}}$ & $3,058^{\mathrm{a}}$ \\
\hline Ração com edulcorante & $849^{\mathrm{a}}$ & $2.774^{\mathrm{a}}$ & $3,295^{\mathrm{a}}$ \\
\hline Água sem edulcorante & $894^{\mathrm{a}}$ & $2.838^{\mathrm{a}}$ & $3,193^{\mathrm{a}}$ \\
\hline \multirow[t]{2}{*}{ Água com edulcorante } & $885^{\mathrm{a}}$ & $2.767^{\mathrm{a}}$ & $3,160^{\mathrm{a}}$ \\
\hline & \multicolumn{3}{|c|}{ Fase total } \\
\hline Ração seca & $755^{\mathrm{a}}$ & $2.051^{\mathrm{a}}$ & $2,726^{\mathrm{a}}$ \\
\hline Ração úmida & $720^{\mathrm{a}}$ & $1.985^{\mathrm{a}}$ & $2,772^{\mathrm{a}}$ \\
\hline Ração sem edulcorante & $753^{\mathrm{a}}$ & $2.001^{\mathrm{a}}$ & $2,668^{\mathrm{a}}$ \\
\hline Ração com edulcorante & $722^{a}$ & $2.035^{\mathrm{a}}$ & $2,823^{\mathrm{a}}$ \\
\hline Água sem edulcorante & $730^{\mathrm{a}}$ & $2.029^{\mathrm{a}}$ & $2,792^{\mathrm{a}}$ \\
\hline Água com edulcorante & $745^{\mathrm{a}}$ & $2.007^{\mathrm{a}}$ & $2,705^{\mathrm{a}}$ \\
\hline
\end{tabular}

Em cada coluna, para cada fator, médias seguidas de letras distintas diferem entre si $(\mathrm{P}<0,05)$ pelo teste de Tukey. leite em pó) em sua composição, caracterizando rações com boa aceitação pelos leitões.

Quanto à ausência de diferença $(P>0,05)$ para o GPD, CDR e CA entre os grupos tratados com rações secas e úmidas (Tabela 2), observa-se uma contradição com os resultados obtidos por WHITTEMORE (1993), HEIMIG (1996) e WASHAM et al. (1998). Entretanto, estes autores estenderam os tratamentos com ração com alta umidade para várias fases (creche, crescimento e terminação), não somente para as três primeiras semanas pósdesmame. Portanto, possivelmente, haja a necessidade da manutenção do tratamento por mais tempo para efetivamente os resultados se apresentarem favoráveis para as dietas úmidas. Essa hipótese pode ser confirmada através dos resultados obtidos por VIEIRA \& CARVALHO (1996), que trabalharam com rações úmidas no período entre 13 a $30 \mathrm{~kg}$ de peso vivo, não observando também diferenças nos dados de desempenho.

Nas primeiras semanas após o desmame a ausência de leite materno pode levar os leitões a um consumo exagerado de ração úmida. Assim, um rápido enchimento gástrico se estabelece e a eficiência e a utilização do alimento passam a ser menores (WILSON \& LEIBHOLZ, 1981). Essa proposição pode auxiliar na compreensão dos resultados que mostram que, no período subsequente ao desmame, os efeitos do uso de rações úmidas não determinam vantagens no desempenho.

Para o CDA, foi observada diferença $(\mathrm{P}<0,05)$ para os tipos de ração, com maior média para o grupo tratado com ração seca. Os resultados estão de acordo com as proposições de HOUPT \& ANDERSON (1990) que destacaram que a água tem seu consumo regulado através de mecanismos osmóticos e orientaram que o tipo de ração influencia o consumo. Ao contrário das rações úmidas, as rações secas favoreceram o consumo de água. Grupos que receberam ração e água com edulcorante, os valores para o CDA foram mais elevados, porém não foram observadas diferenças $(\mathrm{P}>0,05)$.

Esses resultados concordam com a hipótese de McDONALD et al.(1987) que relataram que a adição de edulcorante na água atuava aumentando o seu consumo. STOCKILL (1990) obteve valores de consumo de água três vezes e meia maiores na primeira semana pós-desmame, comparado com tratamentos que ofereciam água isenta de edulcorante $(2200 \mathrm{~m} \ell$ versus $650 \mathrm{~m} \ell)$. 
Tabela 4 - Médias da idade (dias) e transformadas por raiz quadrada $\left(\mathrm{x}^{1 / 2}\right)$ aos $50 \mathrm{~kg} \mathrm{e}$ aos $90 \mathrm{~kg}$ de peso vivo.

\begin{tabular}{lcccc}
\hline Fatores & \multicolumn{2}{c}{ Idade $\operatorname{aos} 50 \mathrm{~kg}$} & \multicolumn{2}{c}{ Idade aos $90 \mathrm{~kg}$} \\
\hline & dias & $\mathrm{x}^{1 / 2}$ & dias & $\mathrm{x}^{1 / 2}$ \\
\cline { 2 - 5 } Ração seca & 88,13 & $9,3841^{\mathrm{a}}$ & 132,43 & $11,5024^{\mathrm{a}}$ \\
Ração úmida & 90,38 & $9,5030^{\mathrm{a}}$ & 137,87 & $11,7365^{\mathrm{a}}$ \\
Ração sem edulcorante & 89,06 & $9,4322^{\mathrm{a}}$ & 132,93 & $11,5221^{\mathrm{a}}$ \\
Ração com edulcorante & 89,44 & $9,4548^{\mathrm{a}}$ & 137,37 & $11,7167^{\mathrm{a}}$ \\
Água sem edulcorante & 90,50 & $9,5099^{\mathrm{a}}$ & 136,18 & $11,6634^{\mathrm{a}}$ \\
Água com edulcorante & 88,00 & $9,3771^{\mathrm{a}}$ & 134,12 & $11,5755^{\mathrm{a}}$ \\
\hline
\end{tabular}

Em cada coluna, para cada fator, médias seguidas de letras distintas diferem entre si $(\mathrm{P}<0,05)$ pelo teste de Tukey.

Os valores do GPD, CDR e CA para as fases inicial II e III, crescimento, terminação e período total (21 dias de idade até $90 \mathrm{~kg}$ de peso vivo) encontram-se na tabela 3 . Em cada fase, para os parâmetros avaliados, não foram observadas diferenças significativas dentro de cada fator e interações significativas entre os fatores. Esses resultados discordam dos valores obtidos por STOCKILL (1990), que inicialmente utilizou água com edulcorante para promover o consumo hídrico e de ração e obteve resultados elevados de ganho de peso até a fase de crescimento. É possível predizer que os efeitos do uso de edulcorante no consumo de água e conseqüentemente no desempenho podem ter resultados variáveis, estando estes relacionados com a qualidade da água utilizada (como seu grau de dureza por exemplo).

Segundo BERTO (1993), o desempenho dos suínos durante a fase inicial não deve ser considerado isoladamente, mas como um componente desde o nascimento até o abate, sendo que o ritmo de crescimento mais lento após o desmame pode ser tolerado desde que os animais se recuperem.

Os valores referentes ao número de dias necessários para os animais atingirem 50 e $90 \mathrm{~kg}$ de peso vivo encontram-se na tabela 4. Para ambos os casos, não foram observadas diferenças entre os tratamentos e nem a interação dos fatores $(\mathrm{P}>0,05)$. Considerando que na saída da primeira fase do experimento (fase inicial I), os grupos não apresentaram ganhos diferenciados, os resultados obtidos mantiveram uma mesma tendência. Nesse sentido, reitera-se a proposição de BERTO (1993), que estabeleceu que os resultados satisfatórios de consumo de ração, ganho de peso e conversão alimentar obtidos nas fases iniciais não representam o todo. O comportamento nas fases subseqüentes pode eliminar os efeitos positivos mais precoces.
Quanto aos resultados de incidência de diarréia, os valores foram maiores $(\mathrm{P}<0,05)$ somente para o grupo tratado com ração seca. Os resultados concordaram com LECCE et al. (1979), que registraram taxas mais elevadas de diarréia e mortalidade em leitões alimentados com ração seca. A maior incidência de diarréia para os leitões tratados com ração seca, todavia, não influenciou negativamente o desempenho dos animais nas fases seguintes.

\section{CONCLUSÃO}

As rações secas exercem um efeito positivo no consumo de água nas primeiras semanas pós-desmame. Já o uso de edulcorante na ração aumenta o consumo de alimento após o desmame, mas os resultados não melhoram o desempenho até os $90 \mathrm{~kg}$ de peso vivo. Por sua vez, a incidência de diarréia nas primeiras três semanas que sucedem o desmame é reduzida pela uso de rações úmidas.

\section{REFERÊNCIAS BIBLIOGRÁFICAS}

ALIMENTO líquido después del destete. In. Porcina, v.14, n.2, p.27, 1994.

ARMSTRONG, M.D., CLAWSON, A.J. Nutrition and management of early weaned pigs: effect of increase nutrient concentration and (or) supplemental liquid feeding. J Anim Sci, v.50, n.3, p.377-384, 1980.

BERTO, D.A. Estudo do ganho de peso compensatório em suínos recebendo no período inicial diferentes tipos de ração e sistemas de alimentação. Jaboticabal, SP, 1993. 131p. Tese (Doutorado em Zootecnia) - Faculdade de Ciências Agrárias e Veterinárias, Universidade Estadual Paulista, 1993.

CUNHA, T.J. Swine feeding and nutrition. New York : Academic, 1977. p.183-189, 255-271.

EMBRAPA. Tabela de composição química e valores energéticos para suínos e aves. 3.ed. Concórdia : CNPSA, 1991. 97p. (Documentos, 19).

FREITAS, H.T, FERREIRA, A.S., DONZELE, J.L. et al. Manejo para desmame de leitões aos 21 dias de idade. R Bras Zootec, v.26, n.4, p.753-758, 1997.

HEIMIG, D. Why $78 \%$ of feeds choose liquid system. Pigs, v.12, n.6, p.9, 1996.

HOUPT, T.R., ANDERSON, C.R. Spontaneous drinking: its estimulated by hipertonicity or hypovolemia? Am J Physiol, v.258, n.1, R143-R148, 1990.

LECCE, J.G., ARMSTRONG, W.D., CRAWFORD, P.C. Nutrition and management of early weaned piglets: liquid $v s$. dry feeding. J Anim Sci, v.48, n.5, p.1007-1014, 1979. 
MAENZ, D.D., PATIENCE, J.F., WOLYNETZ, M.S. Effect of water on the performance of newly weaned pigs offered medicated and unmedicated feed. Can J Anim Sci, n.73, v.3, p.669-672, 1993.

MAKKING, C.A., NEGULESCU, G. P., GUIXIN, Q. et al. Effect of dietary protein source on feed intake, growth, pancreatic enzyme activities and jejunal morphology in newly weaned piglets. Br J Nutr, v.72, n.3, p.353-368, 1994.

McDONALD, P., EDWARDS, R.A., GREENHALGH, J.F.D. Voluntary intake of food. New York : Longman, 1987. Animal Nutrition: p.357-387.

MORES, N., MARQUES, J.L., SOBESTIANSKY, J. et al. Influência do nível protéico e/ou acidificação da ração pós desmame em leitões causada por Escherichia coli. Pesq Vet Bras, v.10, n.3/4, p.85-88,1990.

NRC-NATIONAL RESEARCH COUNCIL. Nutrient requirement of swine. 9.ed. Washington : National Academic, 1988. 93p.

SONCINI, R.A., MADUREIRA JÚNIOR, S.E. Monitorias sanitárias. In: SOBESTIANSKY, J., WENTZ, I., SILVEIRA,
P.R.S., SESTI, L.A. Suinocultura intensiva: produção, manejo e saúde do rebanho. Brasília : EMBRAPA, Sistema de Produção e Informação - SPI, 1998. Cap.5. p.91-110.

STOCKILL, P. Water: whey it should not be the neglected nutrient for pigs. Feed Int, v.11, n.10, p.10-18, 1990.

VIEIRA, A.A., CARVALHO, C.A.B. Ração seca e úmida na alimentação de suínos dos 13 aos $30 \mathrm{~kg}$ de peso vivo. In : REUNIÂO ANUAL DA SOCIEDADE BRASILEIRA DE ZOOTECNIA, 23, 1996, Fortaleza. Anais... Fortaleza : SBZ, 1996. p.174-176.

WASHAM, R.D., PINTO, J.H.E., PASTORE, S., et al. Viabilidade da ração líquida para suínos. São Paulo : PURINA, 1998. (Trabalho apresentado no $3^{\circ}$ Simpósio Internacional de Suinocultura).

WHITTEMORE, C.T. The science and practice of the pig. Longman Scientific e Technical: Essex, 1993. p.4-44, p.357369, 370-392.

WILSON, R.H., LEIBHOLZ, J. Digestion in the pig between 7 and 35 days of age.1. The performance of pigs given milk and soya-bean proteins. Brit J Nutr, v.45, n.2, p.301-319, 1981. 